\title{
Residual Stresses in Different Heat Treated Workpieces after Turning
}

\author{
Markus Lebsanft ${ }^{1, a}$, Marcel Tiffe ${ }^{2, b}$, Andreas Zabel ${ }^{2, ~ c}$, Wolfgang Zinn ${ }^{1, d^{*}}$, \\ Dirk Biermann ${ }^{2, e}$ and Berthold Scholtes ${ }^{1, f}$ \\ ${ }^{1}$ Institute of Materials Engineering, University of Kassel, Germany \\ ${ }^{2}$ Institute of Machining Technology, Technical University of Dortmund, Germany \\ alebsanft@uni-kassel.de, btiffe@isf.de, 'zabel@isf.de, 'dzinn@uni-kassel.de, \\ ebiermann@isf.de, 'scholtes@uni-kassel.de
}

Keywords: quenched and tempered AISI 6150, dry turning, turning forces, residual stresses

\section{Introduction}

The use of short process chains for the realization of complex and high performance components is a reasonable approach to achieve sustainable products and to reduce energy consumption. In the Collaborative Research Center SFB/TR TRR30 which is supported by the German Research Foundation DFG this approach is investigated applying thermo-mechanically forming processes. In this way, combining hot metal forming and heat treatment steps in a single process, tailored materials properties together with appropriate geometries are achieved [1, 2]. However, still additional machining operations, e. g. turning operations in case of shafts, are needed to achieve proper workpiece finish. Due to locally varying mechanical properties, undesired changings of the process conditions occur, leading to varying surface and subsurface properties, e.g. the residual stress state. It is well known that residual stresses have a major impact on the components properties during service [3]. In this paper, a survey is given about near surface residual stress states after exterior dry turning of differently heat treated cylindrical workpieces made of steel AISI 6150.

\section{Experimental Setup}

Experiments were carried out on a NC-controlled lathe of the type Monforts RNC602. The AISI 6150 specimens were cylindrical with a diameter of $\mathrm{d}=34 \mathrm{~mm}$ and a length of $1=200 \mathrm{~mm}$. The workpieces were quenched and tempered with five different temperatures which resulted in five different hardnesses which are listed in Table 1.

Table 1: Workpiece hardnesses for exterior dry turning experiments

\begin{tabular}{llccc}
\hline \multicolumn{5}{c}{ Workpiece hardness [HV10] } \\
\hline 322 & 415 & 500 & 564 & 680 \\
\hline
\end{tabular}

The cylinders were machined using uncoated polycrystalline boron nitride (PCBN) inserts with the ISO-Code CNGA120408 (see Figure 1). The tool had a chamfer with a width of $b_{\gamma}=0.15 \mathrm{~mm}$ and an angle of $\gamma_{\mathrm{f}}=25^{\circ}$. The tool holder was of the type DCLNL2525 and had a nominal rake angle of $\gamma=-6^{\circ}$ and an effective rake angle of $\gamma=-31^{\circ}$ in the chamfer area. During the machining process the resulting forces were measured by a Kistler 3-component toolholder dynamometer.

Turning experiments after a full factorial design with an additional center point were carried out, completed with an additional parameter set with a higher feed rate. The depth of cut is kept constant at $\mathrm{a}_{\mathrm{p}}=0.25 \mathrm{~mm}$ for residual stress measurements presented in this paper. The parameter values were varied in the following ranges: $\mathrm{f}=0.05 \ldots 0.5 \mathrm{~mm}, \mathrm{a}_{\mathrm{p}}=0.05 \ldots 0.52 \mathrm{~mm}$ and $\mathrm{v}_{\mathrm{c}}=100 \ldots 250 \mathrm{~m} / \mathrm{min}$. The used parameter sets are shown in Table 2. 
Table 2: Parameter sets for exterior dry turning experiments

\begin{tabular}{|c|c|c|c|c|c|c|c|}
\hline \multirow[b]{2}{*}{ Set } & \multicolumn{3}{|c|}{ Latin hyper cube design } & \multicolumn{4}{|c|}{$\begin{array}{c}\text { Experimental design for residual stress } \\
\text { measurement }\end{array}$} \\
\hline & $\begin{array}{c}\text { feed } \\
\mathrm{f}[\mathrm{mm}]\end{array}$ & $\begin{array}{l}\text { depth of cut } \\
\mathrm{a}_{\mathrm{p}}[\mathrm{mm}]\end{array}$ & $\begin{array}{l}\text { cutting speed } \\
\mathrm{v}_{\mathrm{c}}[\mathrm{m} / \mathrm{min}]\end{array}$ & Set & $\begin{array}{c}\text { feed } \\
\mathrm{f}[\mathrm{mm}]\end{array}$ & $\begin{array}{l}\text { depth of cut } \\
\mathrm{a}_{\mathrm{p}}[\mathrm{mm}]\end{array}$ & $\begin{array}{l}\text { cutting speed } \\
\mathrm{v}_{\mathrm{c}}[\mathrm{m} / \mathrm{min}]\end{array}$ \\
\hline 1 & 0.5 & 0.46 & 180 & 17 & 0.05 & 0.25 & 100 \\
\hline 2 & 0.17 & 0.36 & 185 & 18 & 0.05 & 0.25 & 250 \\
\hline 3 & 0.14 & 0.4 & 135 & 19 & 0.125 & 0.25 & 175 \\
\hline 4 & 0.3 & 0.27 & 245 & 20 & 0.2 & 0.25 & 100 \\
\hline 5 & 0.43 & 0.43 & 140 & 21 & 0.2 & 0.25 & 250 \\
\hline 6 & 0.28 & 0.33 & 105 & (and) 4 & 0.3 & 0.27 & 245 \\
\hline 7 & 0.37 & 0.3 & 175 & & & & \\
\hline 8 & 0.1 & 0.11 & 155 & & & & \\
\hline 9 & 0.12 & 0.2 & 230 & & & & \\
\hline 10 & 0.41 & 0.14 & 110 & & & & \\
\hline 11 & 0.38 & 0.52 & 205 & & & & \\
\hline 12 & 0.47 & 0.05 & 160 & & & & \\
\hline 13 & 0.44 & 0.24 & 220 & & & & \\
\hline 14 & 0.25 & 0.17 & 150 & & & & \\
\hline
\end{tabular}

Fig. 1: Shape of used tool CNGA120408

Residual stress measurements were carried out by X-ray diffraction technique and the $\sin ^{2} \psi$ method. With $\mathrm{CrK} \alpha$ radiation the $\{211\}$ lattice planes of the ferrite/martensite were measured in the range $148^{\circ}$ to $164^{\circ}$ in $2 \Theta$ for 11 crystal orientations $\psi$ between $-45^{\circ}$ and $+45^{\circ}$. The diffraction angles $2 \Theta_{\psi}$ were calculated from the measured intensity distributions using the sliding gravity method. The illuminated area of the specimen was restricted by a collimator with a diameter of 1 $\mathrm{mm}$. The X-ray elastic constant $1 / 2 \mathrm{~S}_{2}=6.0910^{-6} \mathrm{~mm}^{2} / \mathrm{N}$ was used for stress calculation. Residual stresses of higher order are represented by the mean value of the integral width IW of the diffraction lines. To measure the residual stress depth distribution a stepwise electrolytical layer removal was carried out. The axial (parallel to the turning groove) and tangential (perpendicular to the turning groove) stress components were measured on each new surface. No additional correction for layer removal was applied.

\section{Experimental Results}

Cutting force components $F_{c}, F_{f}$ and $F_{p}$ were systematically modeled as a function of feed $f$, depth of cut $a_{p}$ and cutting speed $v_{c}$ for specimens of hardness 322 HV10 and 700 HV10. Regarding the cutting force $F_{c}$ it can be noticed that the values increase with increasing feed for both materials states. The cutting force is also increased when applying higher depths of cut. The dependency of the cutting force on parameters feed $\mathrm{f}$ and depth of cut $\mathrm{a}_{\mathrm{p}}$ is correlated with the cross-section of the undeformed chip, which is determined by $f$ and $a_{p}$. On the other hand the cutting speed $v_{c}$ seems to have a negligeable influence on the cutting force. When comparing the results for $322 \mathrm{HV} 10$ and 700 HV10 it can be seen that higher hardness leads to higher cutting forces. This can be explained by the higher resistance against shearing of the martensitic structure compared to the softer ferriticpearlitic structure. 
The measured cutting, feed and passive forces of the experiments for residual stress examination for each heat treatment are illustrated in Figure 2, 3 and 4. In Figure 2 the cutting force $F_{c}$ increases with higher feeds, which is in agreement with the modeled forces. For a cutting speed of $\mathrm{v}_{\mathrm{c}}=100 \mathrm{~m} / \mathrm{min}$ and a feed of $\mathrm{f}=0.05 \mathrm{~mm}$ the measured cutting force is highest with $\mathrm{F}_{\mathrm{c}}=98 \mathrm{~N}$ for the workpiece with a hardness of 415 HV10. In case of the other cutting conditions, the highest cutting forces are measured when turning workpieces with hardnesses of 564 HV10 and 680 HV10. This observation underlines the previously mentioned effect of higher forces for the two hardest materials due to their higher toughness. The high cutting force for $415 \mathrm{HV} 10$ may be explained by the high ductility of the softer material in combination with the high negative rake angle in the chamfer area of the tool, which can lead to ploughing effects.

The measured feed forces are significantly smaller than the cutting forces for all cutting parameters used (see Figure 3). Additionally, the differences between workpieces of different hardness are also smaller for each set of cutting speed and feed. However, it can be seen, that the feed force is lowest for the hardest material with $680 \mathrm{HV} 10$. This observation is more pronounced for a cutting speed of $\mathrm{v}_{\mathrm{c}}=100 \mathrm{~m} / \mathrm{min}$ and feed of $\mathrm{f}=0.05 \mathrm{~mm}$. As it has been stated before, the feed force is highly frictional driven and is supported by adhesive material behavior. This might explain the partly measured lower feed forces for the hardest material. All in all the varying differences of the measured forces between the individual workpieces do not show significant influences of the hardness on the feed force.

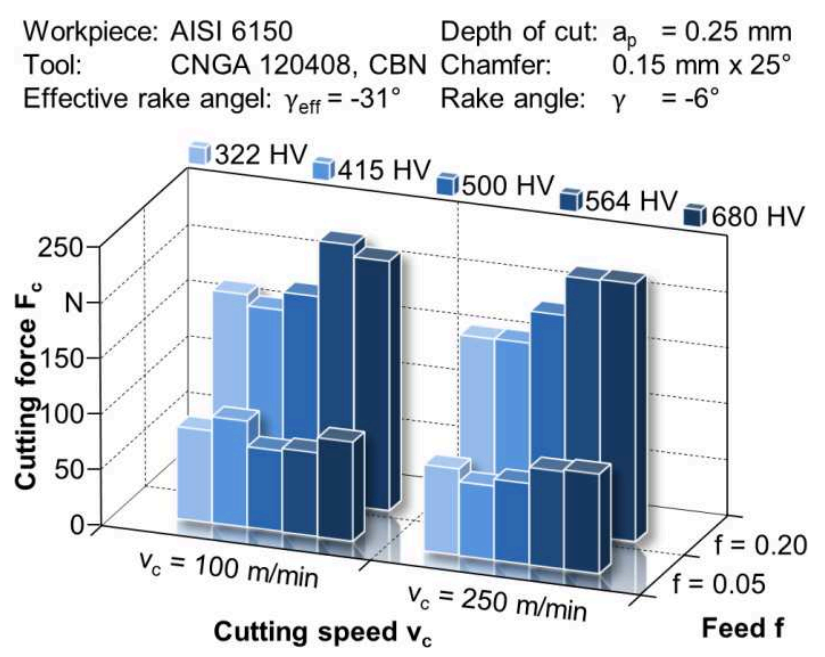

Fig. 2: Measured cutting forces with parameter sets for residual stress analysis

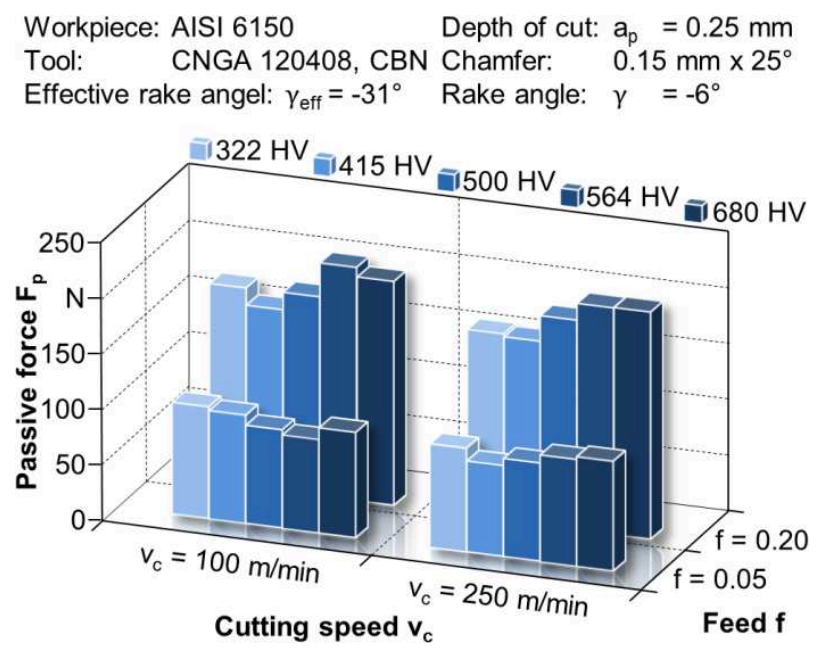

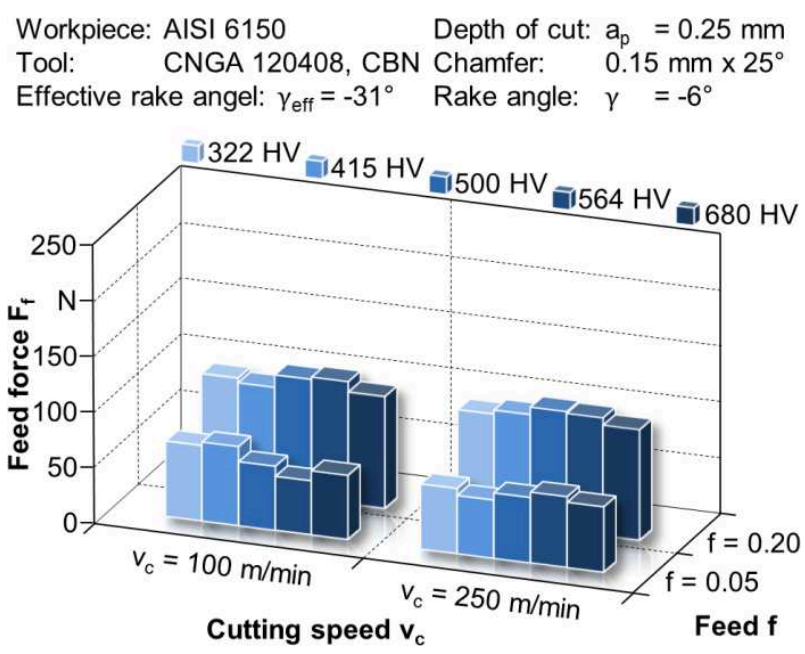

Fig. 3: Measured feed forces with parameter sets for residual stress analysis

Fig. 4: Measured passive forces with parameter sets for residual stress analysis 
The passive force is illustrated in Figure 4. In case of a feed of $\mathrm{f}=0.05 \mathrm{~mm}$ it can be seen that an increasing hardness does not lead to significant higher or lower passive forces. In opposite to this observation, when using higher feeds like $\mathrm{f}=0.2 \mathrm{~mm}$ the passive force is increased for hardnesses of $564 \mathrm{HV}$ and $680 \mathrm{HV}$. Here, the increasing toughness of the material leads to higher mechanical loads, which are directed radially away from the workpiece.

The measured depth distributions of axial and tangential residual stress components are plotted in Figure 5 and 6 for workpieces with a hardness of 322 HV10. Each turning parameter set produces tensile residual stresses in both directions at the direct surface, followed by a compressive residual stresses maximum in different distances from surface. The value of the maximum and the depth below the surface is strongly influenced by the feed $f$ and increases with rising cutting forces, shown in Figure 2 to 4, when the feed rises. The stress gradient is steeper in the case of the axial direction compared with the tangential one. Typically higher values of the local compressive residual stresses are observed perpendicular to the major cutting direction.

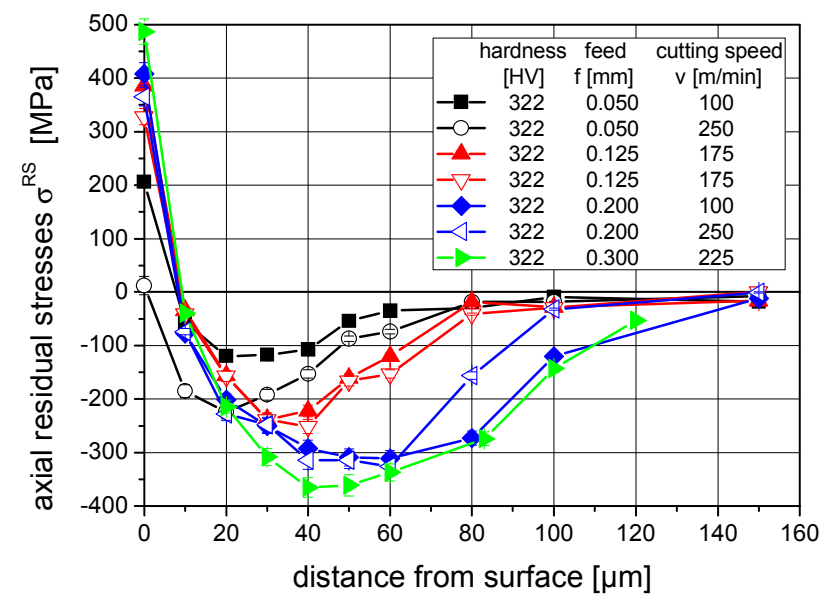

Fig. 5: Depth distributions of axial residual stresses at workpieces with $322 \mathrm{HV} 10$

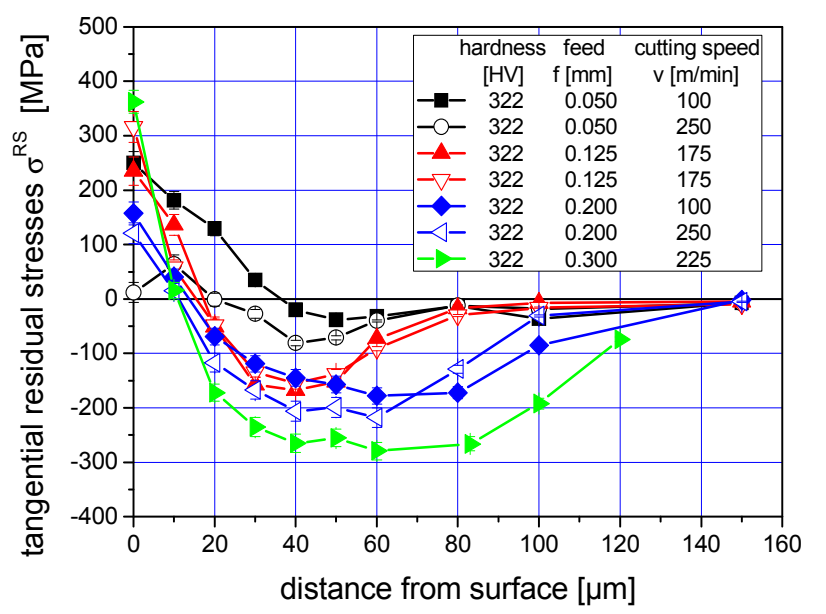

Fig. 6: Depth distributions of tangential residual stresses at workpieces with $322 \mathrm{HV} 10$

In contrast to the specimen with low hardness only compressive residual stresses were measured at the surface in the case of a hardness of $680 \mathrm{HV} 10$ (see Figure 7 and 8). In all cases a local compression maximum is formed in the same manner as for the soft materials state. The influence of a rising feed rate on the surface residual stresses is clearly more pronounced in tangential direction, where a difference of approximately $1000 \mathrm{MPa}$ exists between the lowest and highest feed. The location of the residual stress maximum can be found in a short distance of $10 \mu \mathrm{m}$ to 20 $\mu \mathrm{m}$ from surface.

The residual stress measurements of all of the workpieces with different hardness show a negligible influence of the cutting speed. Only in the case of the soft specimen small differences at small feed rates between the depth distributions are observed. This is in full agreement with the measured cutting forces. 


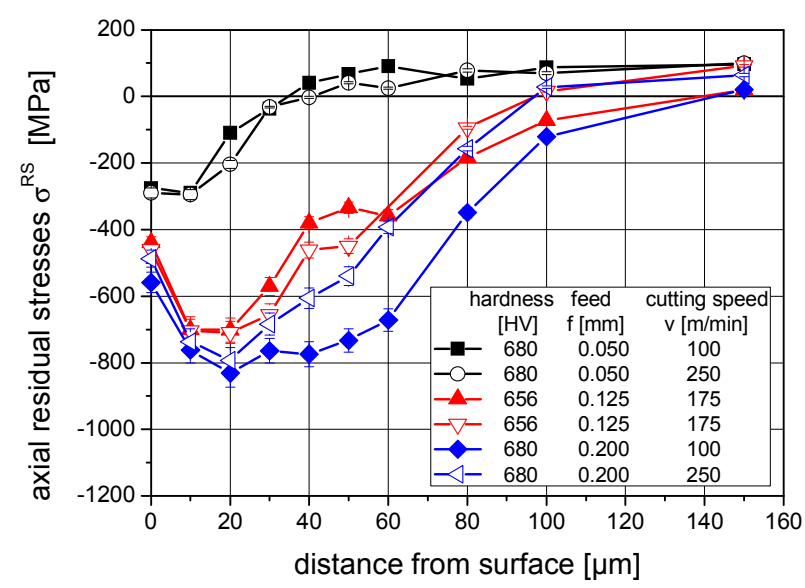

Fig. 7: Depth distributions of axial residual residual stresses at workpieces with $680 \mathrm{HV} 10$

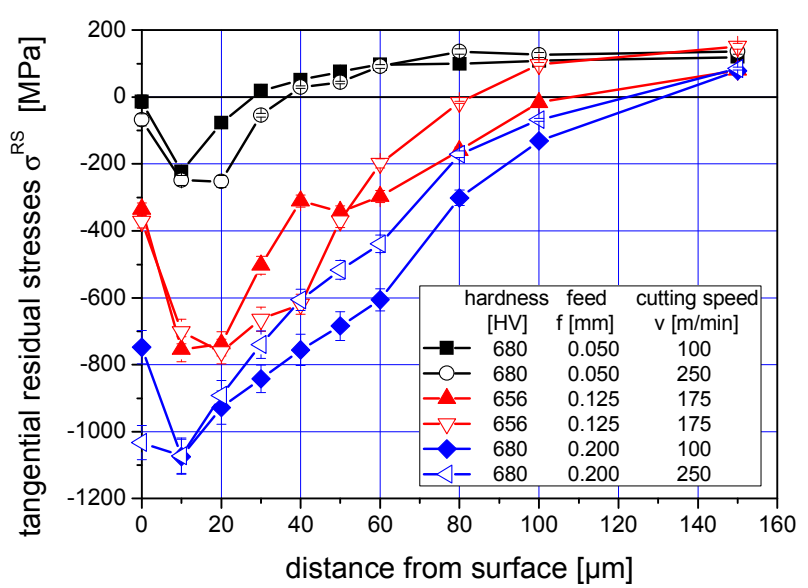

Fig. 8: Depth distributions of tangential residual stresses at workpieces with $680 \mathrm{HV} 10$

The different heat treatments of the investigated material lead to characteristic integral widths IW of the interference lines. These values are influenced by the cutting process. In the case of a soft materials state, the integral width increases near the surface as a result of the rising dislocation density which is due to the cold work process as shown in Figure 8 for a feed of $\mathrm{f}=0.05 \mathrm{~mm}$. In case of higher hardness, as a consequence of the heat treatment process, micro-distortions are pronounced, so that the energy input and potential heat input from plastic deformation leads e.g. to a annihilation of dislocations and lower distortions. This phenomenon reduces the line width. The depth of change of integral width corresponds with the range of plastic deformation as can be seen in Figure 9 for the feed of $\mathrm{f}=0.2 \mathrm{~mm}$. At a hardness of approximately $500 \mathrm{HV}$, neither a cold work nor a softening occurs.

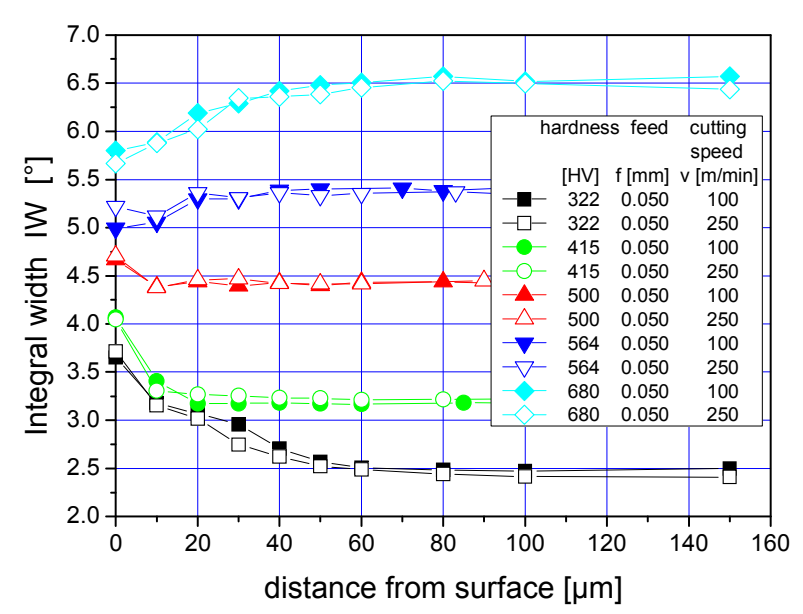

Fig. 8: Integral width depth distributions at a feed rate of $\mathrm{f}=0.05 \mathrm{~mm}$

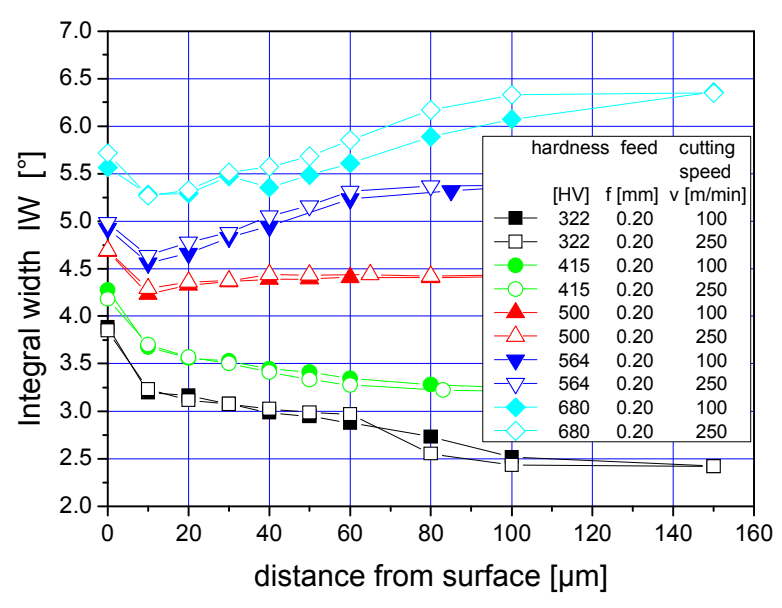

Fig. 9: Integral width depth distributions at a feed rate of $\mathrm{f}=0.2 \mathrm{~mm}$ 


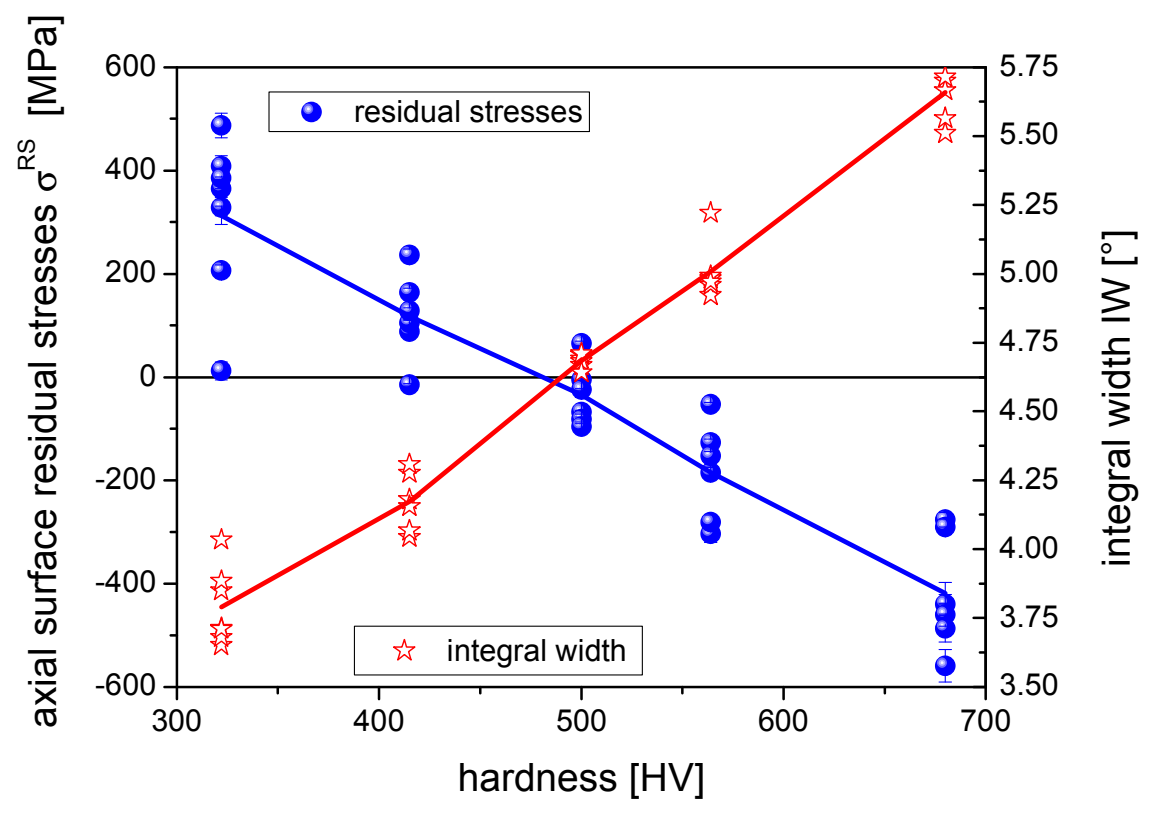

Fig. 10: Surface residual stresses and integral widths as a function of hardness

\section{Summary}

In functionally graded materials due to locally varying process conditions position-dependent residual stress states have to be expected. In addition, to achieve the desired surface finish and integrity, adapted process parameters have to be applied. Using differently heat treated workpieces made of steel AISI 6150 and a wide range of process parameters, this is investigated for turning operations. Cutting forces were modeled and measured and correlated with residual stress depth distributions as well as depth distributions of integral widths of interference lines. As a characteristic result, Fig. 10 shows that surface residual stresses and integral widths are clearly correlated with the materials hardness.

\section{Acknowledgement}

The authors gratefully acknowledge the support of this work by the German Science Foundation DFG in the frame of SFB/TR TRR 30 "Process-integrated production of functionally graded structures on the basis of thermo-mechanically coupled phenomena".

\section{References}

[1] H.-P. Heim, D. Biermann, H. J. Müller: Proceedings 1st International Conference on ThermoMechanically Graded Materials, Verlag Wissenschaftliche Scripten, Auerbach, Germany, 2012, ISBN: 978-3-942267-58-8

[2] H.-P. Heim, D. Biermann, W. Homberg:Functionaly Graded Materials in Industrial Mass Production, Vol. 2, Verlag Wissenschaftliche Scripten, Auerbach, Germany, 2013, ISBN: 9783-942267-91-5

[3] Hashimoto F, Guo YB, Warren AW (2006) Surface Integrity Difference between Hard Turned and Ground Surfaces and its Impact on Fatigue Life. CIRP Annals - Manufacturing Technology 55/1:81-84. doi: 10.1016/S0007-8506(07)60371-0 